\title{
Matching actual treatment with patient administration-route-preference improves analgesic response among acute-low-back-pain patients
}

\section{Adi Shani}

Galilee Medical Center

Michal Granot

University of Haifa

Gleb Mochalov

Galilee Medical Center

Bennidor Raviv

Galilee Medical Center

Nimrod Rahamimov ( $\nabla$ nimrodr@gmc.gov.il)

Galilee Medical Center https://orcid.org/0000-0003-4712-0010

Research article

Keywords: Back pain, placebo, patient preference, individualized medicine, administration route preference

Posted Date: July 17th, 2019

DOl: https://doi.org/10.21203/rs.2.11509/v1

License: (c) (1) This work is licensed under a Creative Commons Attribution 4.0 International License. Read Full License 


\section{Abstract}

Background Accommodating a patient's treatment preference has been reported to promote greater responsiveness and better clinical outcomes. The effect of administration-route-preference (ARP) on the individual analgesic response has not been extensively examined to date. This study aimed to explore whether ARP-matched treatment i.e. individualized intramuscular (IM) or oral (PO) analgesic administration according to patient choice, would increase the analgesic effect. Methods 38 patients with acute-low-back-pain (aLBP) presenting at the emergency room, reported their ARP for analgesics, and, regardless of their initial desire, were randomly assigned to receive either PO or IM diclofenac. Pain intensity was self-reported using the numeric pain score (NPS) before and during the first hour after drug administration. Results Both groups receiving PO or IM administration reported similar initial pain, (NPS $8.63 \pm 1.5$ and $8.74 \pm 1.6$ respectively (and magnitude of pain reduction. However, patients who received the drug in their desired route (oral or injection) had a significantly greater reduction in pain levels $(4.05 \pm 2.8)$ as compared with patients who received the undesired route $(2.08 \pm 1.8) p<0.05$. Conclusions These findings support the hypothesis that individualized ARP-matching treatment in aLBP improves therapeutic outcomes, potentially by triggering an additive analgesic placebo reaction above the direct pharmacological effect alone.

\section{Background}

Current clinical practice guidelines advocate avoiding painful administration of analgesic therapy ${ }^{1}$ thus favoring oral administration over intramuscular injections. As some patients prefer injections and perceive them as being more beneficial than oral therapy ${ }^{2}$, adhering to guidelines can come in contrast with the patient-centered trends of recent years and the attempt to individualize treatment ${ }^{3}$.

Past research has established that patients who receive treatment according to their preference demonstrate significantly more satisfaction and greater improvement in clinical outcomes compared to those who were not treated according to their preference ${ }^{4-6}$, or those who had no preference at all ${ }^{4}$.

Greater satisfaction and improvement are assumed to operate through mechanisms attributed to the placebo response i.e. positive expectation and past experience and beliefs (conditioning) 4 . It is currently accepted that the placebo response refers to the physiological processes experienced following the recognition of being treated, and not as a result of the inert procedure in itself ${ }^{3}$. Therefore, many medical treatments or medical rituals themselves may include a component of placebo response ${ }^{7}$.

Prior experience, knowledge and beliefs that shape positive expectations and conditioning, are known to be key components in the placebo response ${ }^{7}$ and are also involved in the formation of treatment preference ${ }^{8}$ which can relate to both the type of medication and the mode of its delivery. While medication preference has been studied in this context in the past, the individualized administration route preference (ARP), and analgesic ARP have been investigated far less $2,9,10$. 
Our research hypothesis was that the ARP itself is a theraputic ritual which can encompass key components of the placebo effect (i.e. expectation and conditining). Thus, administering the same medication in the preferred ARP will increase the analgesic perception, essentially: "if you believe a certain ARP is better, it will be better for you". As such, the aim of this study was to explore whether an addeitive effect will be observed when an analgesic is received in a patient's ARP, as compared to the same therapeutic agent when received in an undesired method.

\section{Methods}

This was a randomised prospective case series performed at our emergency department.

Included were literate adults, 18 to 80 years old, who presented with acute low back pain (aLBP) defined as non-radicular pain, located in the lumbar spine of a one month duration or less, with no so-called "red flags" suggesting severe organic pathology ${ }^{11}$.

Excluded were patients diagnosed differently or having a known sensitivity to diclofenac.

Patients were asked to report their ARP (oral administration vs. intramuscular injection), and their initial numeric pain score (NPS) on a scale of 0-10.

All Patients received a single dose of either intramuscular diclofenac $75 \mathrm{mg}$ (Abitren ${ }^{\circledR}$ Teva $75 \mathrm{mg} / 3 \mathrm{ml}$, Israel), or $100 \mathrm{mg}$ diclofenac, orally (Betaren ${ }^{\circledR} 100 \mathrm{SR}$, Dexel, Israel). The dosage differences were in accordance with the recommendations in the literature to adjust for differences in the absorption rate between the digestive system where only $65 \%$ to $75 \%$ of the active ingredient reaches the bloodstream ${ }^{12}$ and the muscular tissue.

As either IM or PO diclofenac are routinely used at our emergency department in the treatment of aLBP, randomization to receive one or the other (regardless of the initial analgesic ARP), was done according to the usual choice of the treating on-call resident physician, blinded to the ARP noted by the patient. Demographic and medical information was collected using a questionnaire, and numeric pain scores (NPS, 0-10) were collected every 10 minutes during the first hour following the analgesic administration.

Statistical analyses:

The statistical analysis was performed using IBM SPSS (SPSS Inc., Chicago, IL, USA, version 23). The patients were divided according to their preference (i.e. IM or PO) and also according to the actual administration route, "matched" being patients where the actual administration route matched their preference whereas "non-matched" being patients in which the actual administration route did not match their preference. Dichotomic or discrete data were described by frequencies and percentages. Continuous variables were described by mean, standard deviation and range. Comparisons of binary characteristics between the groups were examined by Chi square test and comparisons of quantitative characteristics 
were performed by Independent sample t- test. $P$ value less than 0.5 was considered as a significant result. Two tailed $P$ values were noted.

\section{Results}

Included were 38 patients meeting our inclusion criteria (illustration 1), of whom 25 patients received IM diclofenac and $13 \mathrm{PO}$.

Both groups were identical in demographic characteristics. No differences were found in mean pain levels, and both groups reported similar severe initial pain, (NPS $8.63 \pm 1.5$ and $8.74 \pm 1.6$ respectively) as well as similar magnitude of pain reduction. (Graph 1).

As illustrated in table 1, 4 groups of preference were created:

A. Patients who preferred and received oral treatment $(n=9)$

B. Patients who preferred intramuscular injections and received oral treatment $(n=4)$

C. Patients who preferred oral treatment and received intramuscular injection $(n=12)$

D. Patients who preferred and received intramuscular injection $(n=13)$

Since group B was too small to perform statistical analysis, the four groups were re-divided into two groups:

1. Patients who were treated according to their ARP's - whether oral treatment or intramuscular injection (groups $A \& D, n=22$ );

2. Patients who received treatment that did not match their ARP's (groups $B \& C, n=16$ ).

When the NPS reduction was examined according to this division, a greater reduction in pain levels was observed in the group of patients treated according to their preference compared with those who received treatment that did not match their preference at 20 minutes post-adminstration,reaching statistical significance at 50 minutes $\left(\mathrm{t}_{(34.099)}=-2.458, \mathrm{P}=0.019\right)$, and remaining significant at 60 minutes $\left(\& \mathrm{t}_{(36)}=\right.$ $-2.232, \mathrm{P}=0.032$ ) as well (graph 2).

When divided into groups according to the administration method, the intramuscular group was larger than the oral group. Therefore, in order to rule out the posibility that the effect was due to the injection itself, the group of patients who received IM medication according to their preference $(n=13)$, was compared to the group of patients who received oral medication according to their preference $(n=9)$ (graph 3), with no difference found between these two groups, suggesting that the injection itself was not the key component of the finding. 
In addition to the observed statistical significance, it is also important to note that the difference between ARP matched and non-matched groups exceeded the 1.9/10 minimal clinical important difference (MCID) in NPS as defined by the US Food and Drug Administration (FDA) ${ }^{13}$ The mean reduction in pain levels in the non-matched ARP group was 1.92 after 50 minutes, and 2.08 after 60 minutes. In the matched ARP group, the pain reduction was more pronounced, with reduction of 3.6 and 4.05 points, respectively (at 50 minutes ( $p=0.019)$ and at 60 minutes ( $p=0.032$ two tailed).

\section{Discussion}

Our study has found that ARP-matching produces at one hour post treatment an NPS reduction difference of more than two points (or two-fold) better reduction when compared to non ARP-matched treatment, although initial pain levels were similar. As there was no difference in analgesic effect between the administration method groups when given according to the ARP's, it can be assumed that it is not the administration method per-se which led to the significance of the findings, but rather the ARP matching.

Our underlying assumption is that preference is associated with prior knowledge, attitudes, belief, learning, and conditioning, and therefore expresses an expectation of a positive effect of the preferred treatment. All of these have been associated with endogenous processes that promote recovery ${ }^{19}$. Furthermore, expectation, learning and conditioning are known to be key components of the placebo phenomenon ${ }^{20-22}$. It is therefore possible that the analgesic improvement demonstrated in this study also involves a placebo response.

Our findings also support shared decision making regarding treatment, and emphasize the importance of considering other factors that shape the experience of pain other than the physiological aspect 26,27 .

Intramuscular administration may augment pain reduction due to activation of descending pain inhibition, as by the pain-inhibit-pain phenomena, in which the pain evoked by the needle activates desecnding pain pathways ${ }^{14-16}$ suppressing pain. In addition, the 'needle effect' 17,18 in which the injection trauma itself is thought to instigate an analgesic response, may in be part of the results found.

Our study has several limitations, the most notable of which is the small sample size which limited the statistical comparisons which could be performed.

Since the treatment given in this study was mostly by Orthopedics residents on call, another limitation is the variability of caregivers, the amount of time they had to interact with the patients and their personal ability to convey compassion and trust - key elements in clinical practice success.

Due to these limitations, we can not argue that the adjustment of the ARP to the treatment given, regardless of the type of treatment or method of administration, is solely responsible for the outcome. To establish this, further studies with larger samples are needed. 


\section{Conclusions}

The findings of our current study support previously published data that treatment based on patient preference improves therapeutic and analgesic outcomes ${ }^{23-25}$, and adds the administration-routepreference as an additional consideration for the practitioner when perscribing analgesic treatment.

\section{Abbreviations}

ARP - Administration Route Prefrence

IM - intramuscular

PO - per os

aLBP - acute low back pain

NPS - numeric pain score

\section{Declarations}

\section{Ethics approval and consent to participate}

This study was approved by the Galilee Medical Center's institutional review board, ref. \# 0032-19-NHR dated march 14th 2019.

As treatment did not differ from normal practice and patients were only asked to fill in an anonymous questionnaire, informed consent to participate in the study was not required by the IRB.

\section{Consent for publication}

No individual patient data, images, videos or voice recordings were collected. Consent for publication is therefore not required.

\section{Availability of data and material}

All data is provided in the manuscript and tables. There is no supplementary data or material.

\section{Competing interests}

None of the authors have competing interests. 


\section{Funding}

No external funding was received in connection with this research.

\section{Authors' contribution}

Adi Shani: co-concieved the research hypothesis and study design, provided background research, submitted IRB request, overviewed data collection and wrote the draft manuscript

Michal Granot. co-concieved the research hypothesis and study design, provided background research, edited the draft manuscript

Gleb Muchalov. Assisted in study planning, collected the data in the emergency room, assisted statistical analysis and draft manuscript preparation.

Bennidor Raviv. Assisted in study planning and data collection.

Nimrod Rahamimov. co-concieved the research hypothesis and study design, provided background research, overviewed statistical analysis, edited draft and wrote final manuscript.

\section{Acknowledgments}

We wish to thank Ms. Orly Yakir for performing the statistical analysis and her helpful suggestions

\section{References}

1. Chou R, Gordon DB, de Leon-Casasola OA, et al. Management of Postoperative Pain: A Clinical Practice Guideline From the American Pain Society, the American Society of Regional Anesthesia and Pain Medicine, and the American Society of Anesthesiologists' Committee on Regional Anesthesia, Executive Commi. J Pain. 2016;17(2):131-157. doi:10.1016/j.jpain.2015.12.008 [doi]

2. Fosnocht DE, Hollifield MB, Swanson ER. Patient preference for route of pain medication delivery. $J$ Emerg Med. 2004;26(1):7-11. doi:10.1016/j.jemermed.2003.03.002

3. Ring D, Bozic KJ. Value-based Healthcare: The Value of Considering Patient Preferences and Circumstances in Orthopaedic Surgery. Clin Orthop Relat Res. 2016;474(3):633-635. doi:10.1007/s11999015-4648-4 [doi]

4. Group PCR. Patients' preferences within randomised trials: systematic review and patient level metaanalysis. BMJ. 2008;337:a1864. doi:10.1136/bmj.a1864 [doi] 
5. Lazaridou A, Edwards RR. Getting personal: the role of individual patient preferences and characteristics in shaping pain treatment outcomes. Pain. 2016;157(1):1-2.

doi:10.1097/j.pain.0000000000000376 [doi]

6. Lindhiem O, Bennett CB, Trentacosta CJ, McLear C. Client preferences affect treatment satisfaction, completion, and clinical outcome: a meta-analysis. Clin Psychol Rev. 2014;34(6):506-517.

doi:10.1016/j.cpr.2014.06.002 [doi]

7. Palese A, Cadorin L, Testa M, Geri T, Colloca L, Rossettini G. Contextual factors triggering placebo and nocebo effects in nursing practice: Findings from a national cross-sectional study. J Clin Nurs. 2019. doi:10.1111/jocn.14809

8. Street Jr RL, Elwyn G, Epstein RM. Patient preferences and healthcare outcomes: an ecological perspective. Expert Rev Pharmacoecon Outcomes Res. 2012;12(2):167-180. doi:10.1586/erp.12.3 [doi]

9. Mitsikostas DD, Belesioti I, Arvaniti C, et al. Patients' preferences for headache acute and preventive treatment. J Headache Pain. 2017;18(1):102. doi:10.1186/s10194-017-0813-3

10. Wong A, Kraus PS, Lau BD, et al. Patient preferences regarding pharmacologic venous thromboembolism prophylaxis. J Hosp Med. 2015;10(2):108-111. doi:10.1002/jhm.2282

11. Oliveira CB, Maher CG, Pinto RZ, et al. Clinical practice guidelines for the management of non-specific low back pain in primary care: an updated overview. Eur Spine J. 2018;27(11):2791-2803. doi:10.1007/s00586-018-5673-2

12. Todd PA, Sorkin EM. Diclofenac sodium. Drugs. 1988;35(3):244-285.

13. Olsen MF, Bjerre E, Hansen MD, et al. Pain relief that matters to patients: systematic review of empirical studies assessing the minimum clinically important difference in acute pain. BMC Med. 2017;15(1):33-35. doi:10.1186/s12916-016-0775-3 [doi]

14. Le Bars D, Dickenson AH, Besson J-M. Diffuse noxious inhibitory controls (DNIC). I. Effects on dorsal horn convergent neurones in the rat. Pain. 1979;6(3):283-304.

15. Granot M, WeissmanFogel I, Crispel $Y$, et al. Determinants of endogenous analgesia magnitude in a diffuse noxious inhibitory control (DNIC) paradigm: Do conditioning stimulus painfulness, gender and personality variables matter? Pain. 2008;136(1-2):142-149. http://ovidsp.ovid.com/ovidweb.cgi? $T=J S \& C S C=Y \& N E W S=N \& P A G E=$ fulltext\&D=ovftj\&AN=00006396-200805000-00018.

16. Yarnitsky D. Conditioned pain modulation (the diffuse noxious inhibitory control-like effect): its relevance for acute and chronic pain states. Curr Opin Anaesthesiol. 2010;23(5):611-615.

doi:10.1097/ACO.0b013e32833c348b [doi] 
17. Dommerholt J, Grieve R, Layton M, Hooks T. An evidence-informed review of the current myofascial pain literature-January 2015. J Bodyw Mov Ther. 2015;19(1):126-137. doi:10.1016/j.jbmt.2014.11.006 [doi]

18. Gattie E, Cleland JA, Snodgrass S. The Effectiveness of Trigger Point Dry Needling for Musculoskeletal Conditions by Physical Therapists: A Systematic Review and Meta-analysis. J Orthop Sports Phys Ther. 2017;47(3):133-149. doi:10.2519/jospt.2017.7096 [doi]

19. Thompson KA, Bulls HW, Sibille KT, et al. Optimism and Psychological Resilience are Beneficially associated with Measures of Clinical and Experimental Pain in Adults with or at Risk for Knee Osteoarthritis. Clin J Pain. 2018. doi:10.1097/AJP.0000000000000642 [doi]

20. Colloca L, Grillon C. Understanding placebo and nocebo responses for pain management. Curr Pain Headache Rep. 2014;18(6):1-7.

21. Munnangi S, Angus LD. Placebo Effect. In: StatPearls. Treasure Island (FL): StatPearls Publishing LLC; 2018. doi:NBK513296 [bookaccession]

22. Price DD, Finniss DG, Benedetti F. A comprehensive review of the placebo effect: recent advances and current thought. AnnuRevPsychol. 2008;59:565-590.

23. Conn VS, Ruppar TM, Enriquez M, Cooper PS. Patient-Centered Outcomes of Medication Adherence Interventions: Systematic Review and Meta-Analysis. Value Health. 2016;19(2):277-285. doi:10.1016/j.jval.2015.12.001 [doi]

24. Coulter A, Entwistle VA, Eccles A, Ryan S, Shepperd S, Perera R. Personalised care planning for adults with chronic or long-term health conditions. Cochrane database Syst Rev. 2015;(3):CD0105(3):CD010523. doi:10.1002/14651858.CD010523.pub2 [doi]

25. Ringdal M, Chaboyer W, Ulin K, Bucknall T, Oxelmark L. Patient preferences for participation in patient care and safety activities in hospitals. BMC Nurs. 2017;16:69-017-0266-7. eCollection 2017. doi:10.1186/s12912-017-0266-7 [doi]

26. Carlino E, Benedetti F. Different contexts, different pains, different experiences. Neuroscience. 2016;338:19-26. doi:S0306-4522(16)00081-6 [pii]

27. Carlino E, Frisaldi E, Benedetti F. Pain and the context. Nat Rev. 2014;10(6):348-355. doi:10.1038/nrrheum.2014.17 [doi]

\section{Tables}

Table 1Legend: Administration route preference vs. actual administration route received 


\begin{tabular}{|c|c|c|c|}
\hline Table 1 & \multicolumn{3}{|c|}{ Administration Route Preference } \\
\hline \multirow{3}{*}{$\begin{array}{l}\text { Actual } \\
\text { Administration } \\
\text { Route }\end{array}$} & & $\begin{array}{c}P O \\
(n=21) \\
\end{array}$ & $\begin{array}{c}\mathrm{IM} \\
(\mathrm{n}=17) \\
\end{array}$ \\
\hline & PO $(n=13)$ & 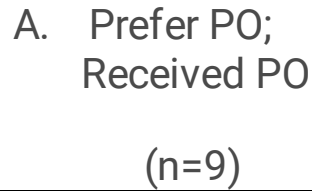 & $\begin{array}{l}\text { B. Prefer IM; } \\
\text { Received PO } \\
(\mathrm{n}=4)\end{array}$ \\
\hline & $\begin{array}{c}\mathrm{IM} \\
(\mathrm{n}=25)\end{array}$ & $\begin{array}{l}\text { C. Prefer PO; } \\
\text { Received IM } \\
(n=12)\end{array}$ & $\begin{array}{l}\text { D. } \text { Prefer IM; } \\
\text { Received IM } \\
(n=13)\end{array}$ \\
\hline
\end{tabular}

\section{Figures}

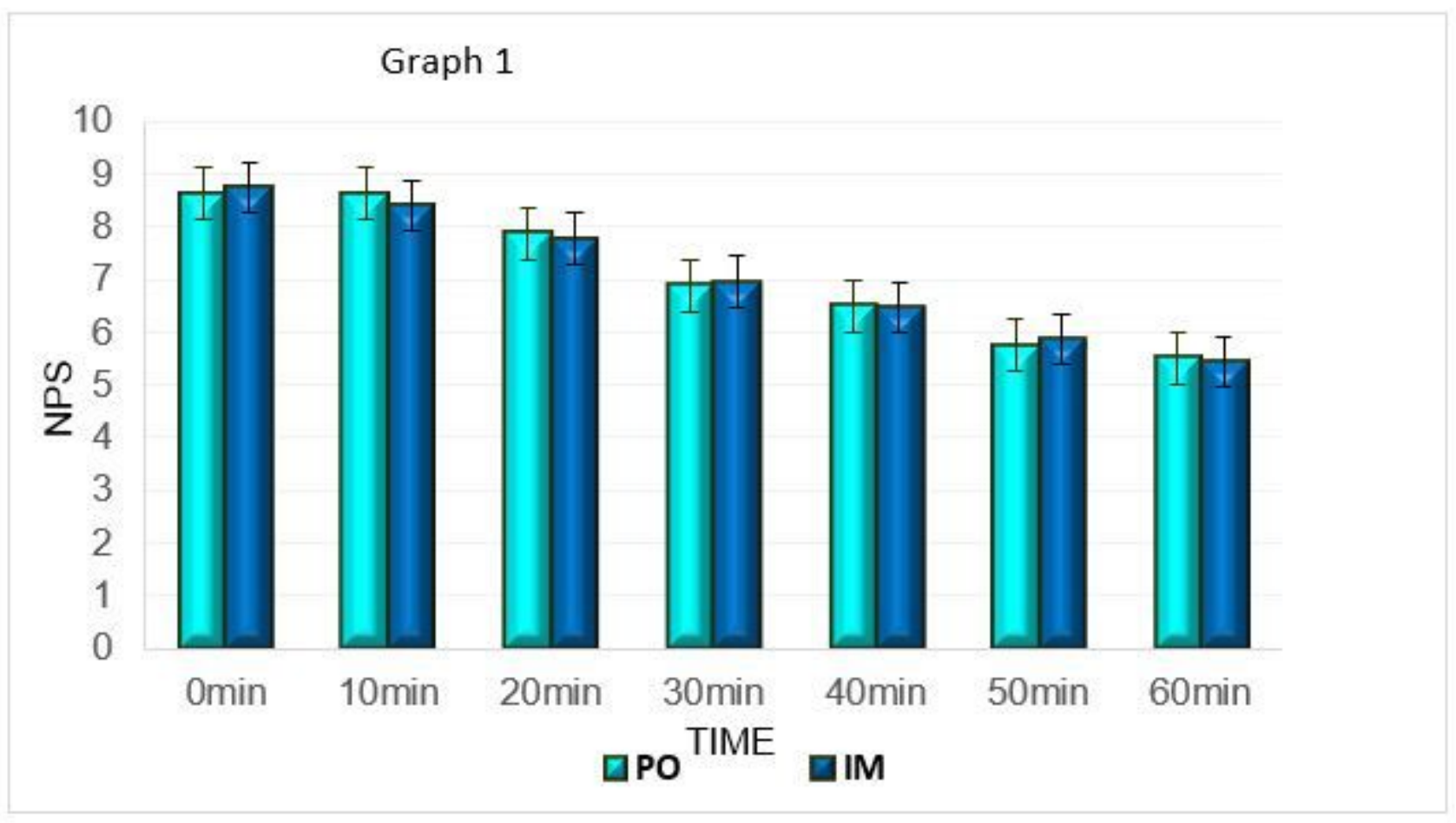

Figure 1

When grouped together, patients receiving diclofenac intramuscularly (IM) or orally (PO) showed similar reduction in their Numeric Pain Score (NPS) over the first post-administration hour. 


\section{Graph 2}

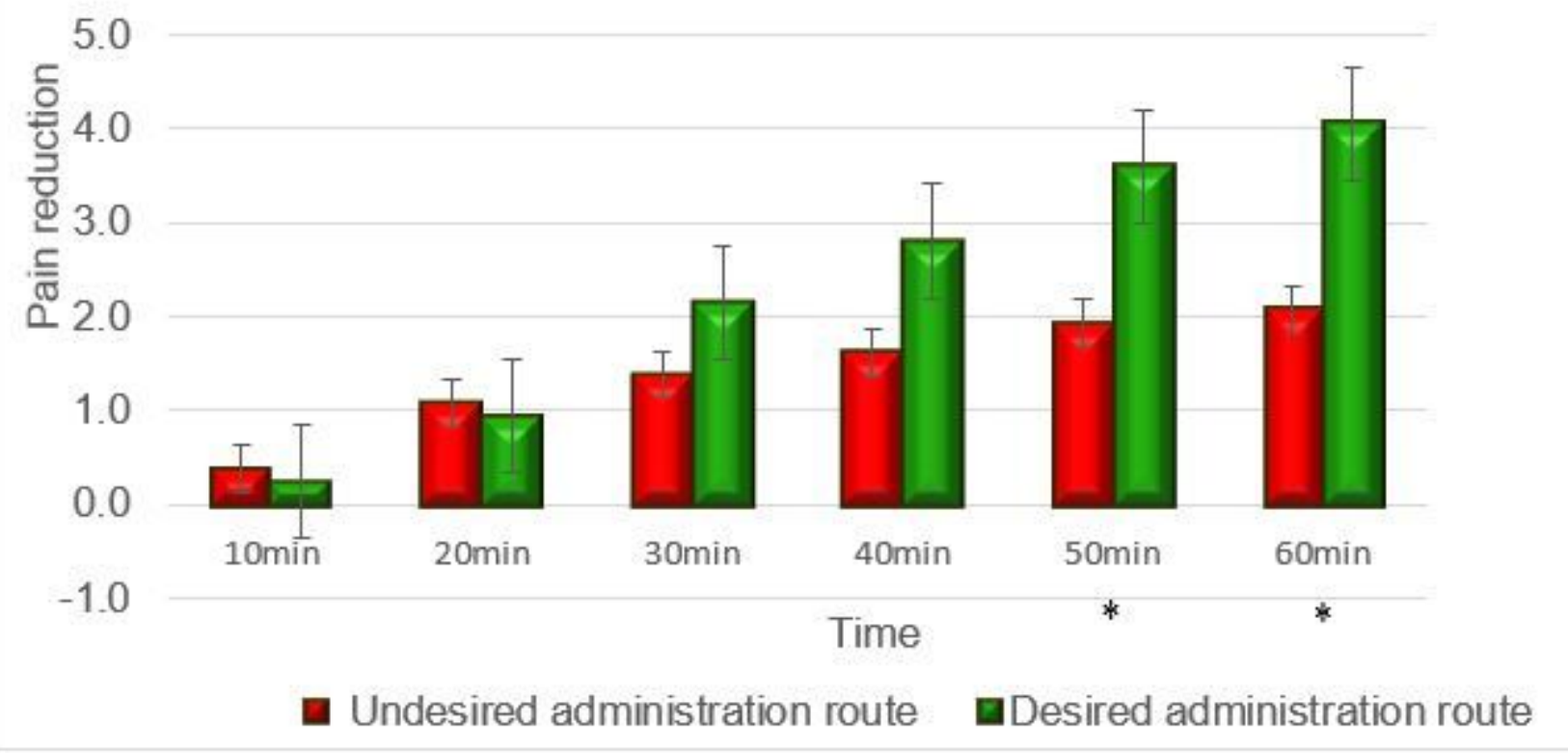

\section{Figure 2}

Patients receiving diclofenac in their desired administration route showed a greater reduction in pain over time when compared to patients receiving diclofenac in their undesired administration route, reaching statistical significance $\left.{ }^{*}\right)$ at 50 minutes post administration.

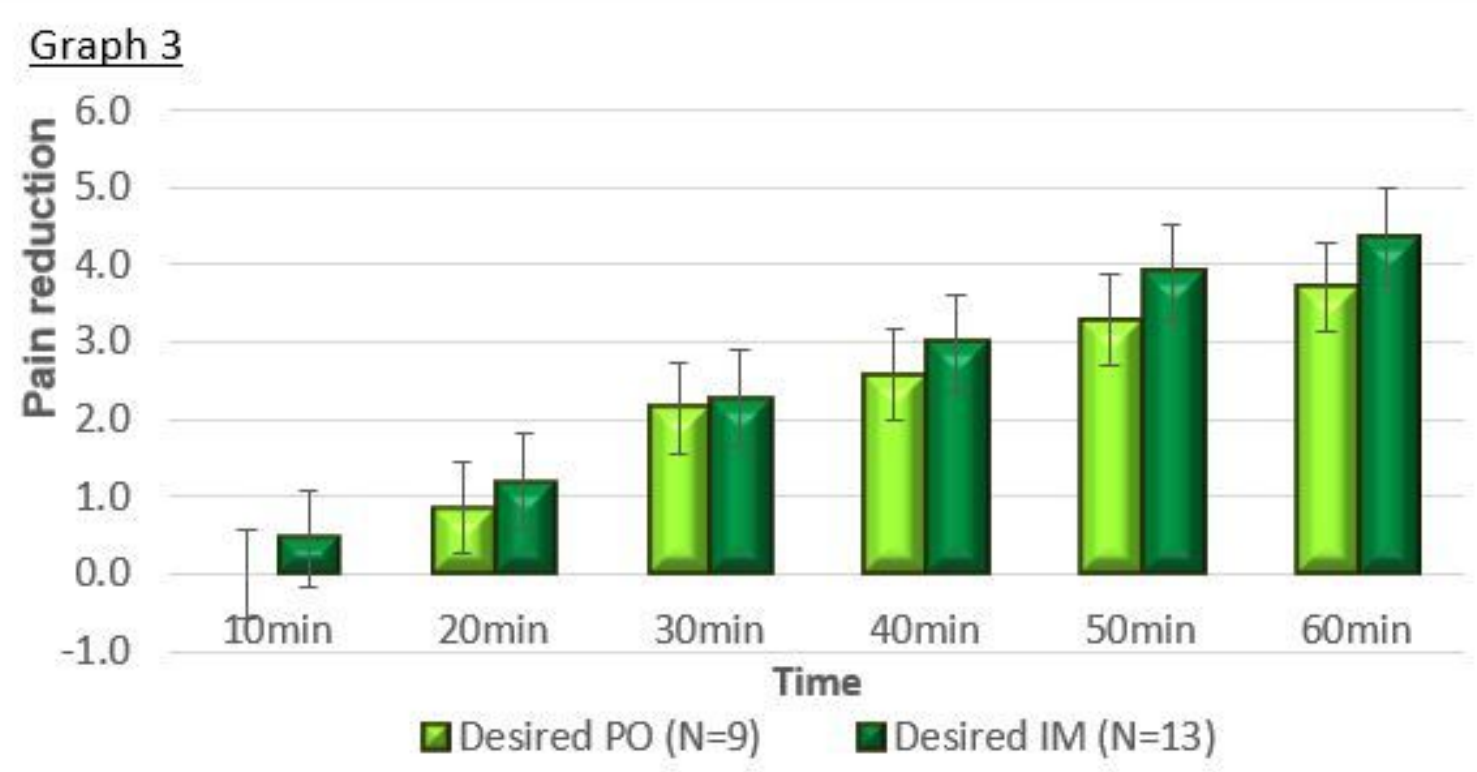

\section{Figure 3}

There was no statistically significant difference in pain reduction between patients receiving diclofenac, regardless of the administration route, when it was administered according to their desired administration 
route.

Page 12/12 